\title{
Physical capability and subsequent positive mental wellbeing in older people: findings from five HALCyon cohorts
}

\author{
Rachel Cooper • Mai Stafford • Rebecca Hardy • Avan Aihie Sayer • \\ Yoav Ben-Shlomo • Cyrus Cooper • Leone Craig • Ian J. Deary • \\ John Gallacher • Geraldine McNeill • John M. Starr • Diana Kuh • \\ Catharine R. Gale $\cdot$ on behalf of the HALCyon study team
}

Received: 14 February 2013 / Accepted: 5 June 2013 /Published online: 2 July 2013

(C) The Author(s) 2013. This article is published with open access at Springerlink.com

\begin{abstract}
Objective measures of physical capability are being used in a growing number of studies as biomarkers of healthy ageing. However, very little research has been done to assess the impact of physical capability on subsequent positive mental wellbeing, the maintenance
\end{abstract}

The HALCyon study team also included Tamuno Alfred, Paula Aucott, Ian Day, Panayotes Demakakos, Jane Elliott, Mike Gardner, James Goodwin, Alison Lennox, Richard M Martin, Carmen Martin-Ruiz, Gita Mishra, Zeinab Mulla, Emily Murray, Sam Parsons, Chris Power, Marcus Richards, Paul Shiels, Humphrey Southall, Andrew Steptoe, Kate Tilling, Vicky Tsipouri, Thomas von Zglinicki and Lawrence J Whalley.

Electronic supplementary material The online version of this article (doi:10.1007/s11357-013-9553-8) contains supplementary material, which is available to authorized users.

R. Cooper $(\bowtie) \cdot$ M. Stafford $\cdot$ R. Hardy $\cdot$ D. Kuh

MRC Unit for Lifelong Health and Ageing,

University College London, 33 Bedford Place,

London WC1B 5JU, UK

e-mail: r.cooper@nshd.mrc.ac.uk

A. Aihie Sayer - C. Cooper · C. R. Gale

MRC Lifecourse Epidemiology Unit, Southampton General

Hospital, University of Southampton,

Southampton, SO16 6YD, UK

Y. Ben-Shlomo

School of Social and Community Based Medicine, University of Bristol, Canynge Hall, 39 Whatley Road, Bristol BS8 2PS, UK

\section{Cooper}

National Institute for Health and Research Musculoskeletal Biomedical Research Unit, University of Oxford,

Oxford, UK of which is widely considered to be an essential component of healthy ageing. We aimed to test the associations of grip strength and walking, timed get up and go and chair rise speeds (assessed at ages 53 to 82 years) with positive mental wellbeing assessed using the Warwick-
L. Craig · G. McNeill

Institute of Applied Health Sciences,

University of Aberdeen, Foresterhill,

Aberdeen AB25 2ZD, UK

I. J. Deary $\cdot$ J. M. Starr $\cdot$ C. R. Gale

Centre for Cognitive Ageing and Cognitive

Epidemiology, Department of Psychology,

University of Edinburgh,

Edinburgh EH8 9JZ, UK

\section{J. Gallacher}

Department of Primary Care and Public Health, Cardiff University, Cardiff CF14 4YS, UK

\section{J. M. Starr}

Geriatric Medicine, University of Edinburgh, Edinburgh EH4 2XU, UK 
Edinburgh Mental Wellbeing Scale (WEMWBS) 5 to 10 years later. Data were drawn from five British cohorts participating in the Healthy Ageing across the Life Course research collaboration. Data from each study were analysed separately and then combined using random-effects meta-analyses. Higher levels of physical capability were consistently associated with higher subsequent levels of wellbeing; for example, a 1SD increase in grip strength was associated with an age and sexadjusted mean difference in WEMWBS score of 0.81 $(0.25,1.37)$, equivalent to $10 \%$ of a standard deviation (three studies, $N=3,096$ ). When adjusted for body size, health status, living alone, socioeconomic position and neuroticism the associations remained albeit attenuated. The finding of these consistent modest associations across five studies, spanning early and later old age, highlights the importance of maintaining physical capability in later life and provides additional justification for using objective measures of physical capability as markers of healthy ageing.

Keywords Physical capability · Positive mental wellbeing · Grip strength · Walking speed - Chair rise time

\section{Introduction}

Objective measures of physical capability including grip strength, walking speed and chair rising ability are being used in a growing number of studies of older people as markers of healthy ageing. This is justified by a range of evidence including systematic reviews and meta-analyses showing that better performance on these tests is associated with lower mortality rates and reduced risk of a range of adverse health outcomes in community-dwelling older populations (Cooper et al. 2010; 2011b; Studenski et al. 2011). However, little research has been done to assess the impact of physical capability on subsequent positive mental wellbeing despite the fact that the maintenance of wellbeing is highly valued by older people (Phelan et al. 2004) and is widely regarded as an essential component of healthy ageing.

In the last decade, the importance of mental wellbeing has been highlighted by a number of agencies including the United Nations, World Health Organisation (2004), the US National Institute on Aging and the UK Government's Foresight Project (2008) (Stiglitz et al. 2009) in response to which Government led initiatives to measure national wellbeing have been introduced (Self et al. 2012). This, alongside the global challenge of the ageing population (Christensen et al. 2009), has made understanding the determinants of mental wellbeing in older people increasingly important and highly policy relevant (Beddington et al. 2008; Forgeard et al. 2011).

Previous cross-sectional analyses within the Healthy Ageing across the Life Course (HALCyon) research programme found that weaker grip strength, shorter balance times and higher levels of disability were consistently associated with higher levels of anxiety and depression across five cohorts (Gale et al. 2011). Associations between lower levels of physical capability and depression have also recently been shown in longitudinal analyses of other studies with some evidence suggesting that these are bi-directional (Li et al. 2012; Sanders et al. 2012). However, outcomes such as anxiety and depression represent only one extreme of the broad spectrum of mental health. Whether factors that are linked with risk of these negative aspects of mental health are also associated with positive mental wellbeing is unclear, especially as it has been shown that, although correlated, a high level of positive mental wellbeing does not guarantee the absence of symptoms of poor mental health (Weich et al. 2011).

The main aim of this study was to examine whether better performance in a range of different objective, continuous measures of physical capability was associated with higher levels of positive mental wellbeing 5 to 10 years later across five British cohorts of people aged 53 to 82 years at baseline.

\section{Methods}

This paper utilises data from five of the nine cohorts participating in the HALCyon research programme (Cooper et al. 2011a; Kuh et al. 2012). Each of these studies included a coordinated assessment of mental wellbeing and also measured physical capability objectively during at least one prior wave of data collection.

The Lothian Birth cohort 1921 (LBC1921)

In 1932, the Scottish Mental Survey administered a wellvalidated general cognitive ability test to almost all Scottish school pupils born in 1921 (mean age 11 years). Members of this cohort were traced in the late 1990s and those still resident in the Lothian (Edinburgh) area of Scotland were recruited to participate in LBC1921. The first wave of new data, which included measurement of 
physical capability, was collected in 1999-2001 when participants were aged 77 to 80 years and wellbeing was assessed during a third wave in 2007-8 when they were aged 85 to 87 years (Deary et al. 2004; 2013).

\section{Caerphilly Prospective Study}

Caerphilly Prospective Study (CaPS) is a cohort of men, born between 1920 and 1939, who were recruited when they were aged 45-59 years, between 1979 and 1983, from the town of Caerphilly and adjacent villages in South Wales (The Caerphilly and Speedwell Collaborative Group 1984). During the second wave, between 1984 and 1988, the original cohort was supplemented with men of a similar age who had moved into the defined area. Physical capability was assessed during a fifth wave of data collection in 2000-4 when participants were aged 65 to 82 years and wellbeing was assessed in 2011 when they were aged 73 to 90 years.

\section{Hertfordshire Cohort Study}

Hertfordshire Cohort Study (HCS) is a cohort of men and women born in Hertfordshire (East, North or West) between 1931 and 1939 whose birth and infant records were available and who were alive and still living in Hertfordshire in the 1990s. The first two new waves of data, which included measurement of physical capability, were collected in 1999-2004 and 2004-5, respectively, when study participants were aged 59 to 74 years (Syddall et al. 2005) and wellbeing was assessed in 2008 when participants were aged 69 to 78 years.

\section{Aberdeen Birth Cohort 1936}

Aberdeen Birth Cohort 1936 (ABC1936) is a cohort of men and women born in 1936 who participated in the Scottish Mental Survey administered to 11year-old school pupils across Scotland in 1947. The cohort were traced in the late 1990s and those still resident in the Aberdeen area of Scotland were invited to participate in ABC1936, with the first wave of new data, which included measurement of physical capability, collected in 1999-2003 when participants were aged 62 to 67 years (Deary et al. 2004) and wellbeing assessed when they were aged 72 to 75 years.
MRC National Survey of Health and Development

The National Survey of Health and Development (NSHD), alternatively known as the 1946 British birth cohort, is a nationally representative sample of people born in England, Scotland, and Wales during 1 week in March 1946 who have been followed up prospectively since birth (Kuh et al. 2011; Wadsworth et al. 2006). Physical capability was assessed during home visits in 1999 at age 53 years and wellbeing has been assessed in a data collection between 2006 and 2011 when participants were aged 60 to 64 years.

\section{Assessment of mental wellbeing}

Wellbeing was assessed in each of the cohorts using the Warwick-Edinburgh Mental Wellbeing Scale (WEMWBS). This 14-item scale has been developed to measure mental wellbeing and has been validated on a representative general population sample of British adults (Tennant et al. 2007). Participants were asked to respond to each of the items, all of which were positively worded (statements including 'I've been feeling optimistic about the future', 'I've been feeling useful' and 'I've been dealing with problems well') by indicating which one of five options ranging from 'none of the time' (score 1) to 'all of the time' (score 5) best described their experience over the last 2 weeks. The overall score, which is calculated by summing the scores for each item, has been shown in confirmatory factor analysis to be measuring a single underlying concept of wellbeing (Tennant et al. 2007), and has a range from 14 (lowest level) to 70 (highest level of mental wellbeing). When summing the scores of individual items to create a total score, values were imputed based on the average score for completed items where there were $\leq 3$ missing items ( $n=2$, LBC1921; $n=43$, CaPS; $n=52$, HCS; $n=84$, NSHD) (Stewart-Brown and Janmohamed 2008). Internal consistency of the scale in all five cohorts was high (Cronbach alpha=0.89 (in LBC1921 and ABC1936), 0.91 (in HCS and NSHD) and 0.93 (in CaPS)).

\section{Assessment of physical capability}

These analyses utilise four objective measures of physical capability assessed at the ages detailed above, which in all cohorts were at ages prior to the assessment of wellbeing; 
grip strength and walking speed were assessed in three cohorts and timed get up and go (TUG) and chair rise speed in two. Harmonisation of each of these measures, to ensure their comparability across cohorts, has been described in detail elsewhere (Cooper et al. 2011a).

Grip strength was measured using a Jamar dynamometer (or North Coast Hydraulic Hand dynamometer in some LBC1921 participants) in LBC1921 and HCS and using the Nottingham electronic handgrip dynamometer in NSHD. The maximum recorded value (in kilograms) was used in analyses.

In LBC21, the time it took participants to walk as quickly as possible over a distance of $6 \mathrm{~m}$ was recorded. In HCS and ABC1936 participants were timed walking at their normal pace over distances of $3 \mathrm{~m}$ and $6 \mathrm{~m}$, respectively. To account for differences in the distances walked, all times were converted to speeds (meters per second). A standard protocol for the TUG test (Podsiadlo and Richardson 1991) which involved getting up from a chair, walking $3 \mathrm{~m}$ at a normal pace, turning around, returning to the chair and sitting back down was used in both HCS and CaPs. TUG speed (meters per second) was then calculated by dividing $6 \mathrm{~m}$ (the distance walked) by the time taken in seconds. In CaPS, two trials of this test had been performed and so the average speed was calculated and used in analyses.

Chair rise performance was measured as the time taken to rise from a sitting to a standing position and then sit down again as fast as possible five complete times in HCS and ten times in NSHD. Chair rise speed (rises/minute) was then calculated by dividing the number of rises performed (i.e., 5 or 10) by the time (in minutes) taken to complete the test.

All four physical capability measures were sexstandardised within cohort for the purposes of the main analyses.

\section{Covariates}

Factors which it was hypothesised may confound the main associations of interest, because they have previously been shown to be associated with both physical capability and/or wellbeing, and that had been assessed in each of the cohorts were selected a priori. These were gender, age, body size (body mass index and height), self-reported health status, living alone (as an indicator of level of support in the home), adult socioeconomic position (occupational class and educational level) and the personality trait neuroticism. The methods of ascertaining the latter five covariates in each cohort are summarised in Table 1. Body size at the time of physical capability assessment was assessed in each cohort using standardised protocols during clinic or nurse home visits.

\section{Statistical analysis}

Associations between each sex-standardised physical capability measure and the WEMWBS score were examined using equivalent linear regression models run separately in each cohort. Random-effects metaanalysis models (DerSimonian and Laird 1986), selected a priori due to expected heterogeneity between studies, were then used to obtain overall estimates of the associations between each measure of physical capability and the WEMWBS score across cohorts. The percentage of variation between studies not attributable to within-study variation was examined using $I^{2}$ (Higgins and Thompson 2002).

Gender interactions and deviations from linearity were tested in age-adjusted models and as there was no evidence of these across cohorts (see supplementary Table 1) all subsequent analyses within each cohort were run with adjustment for gender and assuming linearity. Models were first run with adjustment for age and gender and then with simultaneous adjustment for all covariates. To ensure comparability, all models were run on the samples with complete data on all covariates.

All analyses were performed using STATA, version 10.1 (StataCorp, College Station, TX).

\section{Sensitivity analyses}

Sensitivity analyses were performed in which: (1) results from analyses of walking and TUG speed were combined in the same meta-analyses; (2) each model was rerun using the maximum available sample, to ensure that exclusion of people with missing data on covariates did not introduce bias; (3) the WEMWBS scores of those unable to perform each test of physical capability for health reasons, who were therefore excluded from analyses, were compared with those who were able to perform the test, in those cohorts where this information was available (HCS, CaPS and NSHD) (Cooper et al. 2011a); 


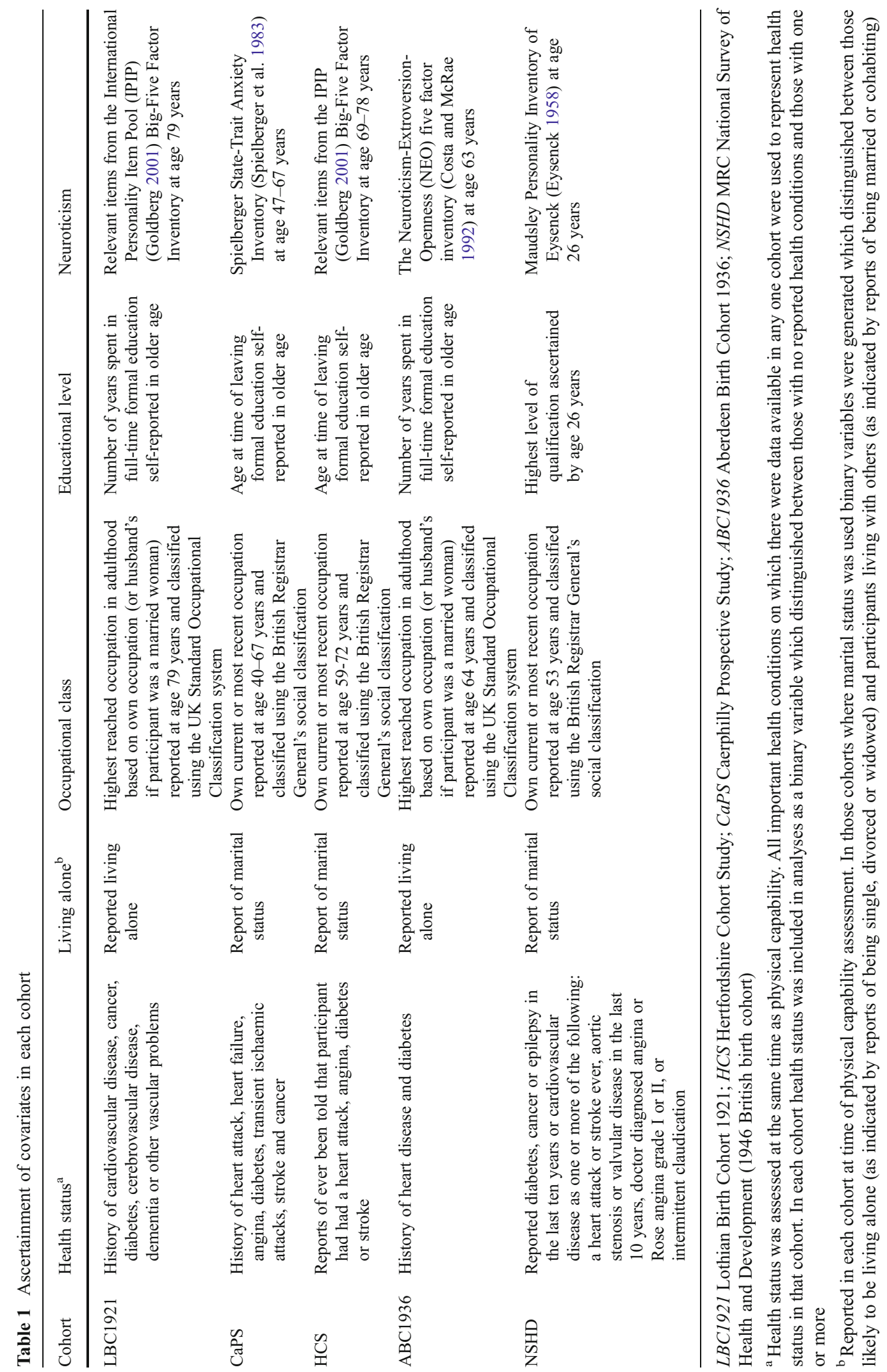


(4) the WEMWBS scores of those who performed the TUG test with a walking aid were compared with those who performed the test unaided.

\section{Results}

Mean levels of physical capability at baseline and wellbeing at follow-up in each of the cohorts are presented stratified by sex in Table 2 . Confirming findings from previous analyses in these cohorts (Cooper et al. 2011a), men were found to have better physical capability levels than women (especially grip strength) and mean levels of physical capability were generally lower in cohorts with older average ages at assessment. There was no evidence of differences in WEMWBS scores by sex (results from $t$ tests of gender differences: $p>0.8$ in all cohorts except HCS where $p=0.17$ ) and mean scores were similar across cohorts, despite the variations in mean age at assessment.

There was consistent evidence across cohorts that better performance on each of the four physical capability measures was associated with higher subsequent levels of wellbeing; estimates from meta-analyses of age and sex-adjusted unstandardized regression coefficients ranged from a mean difference in WEMWBS score of $0.79(0.28,1.30)$ to $1.70(0.49,2.91)$ for every 1SD increase in physical capability (see Table 3 and Fig. 1), which is equivalent to a difference of 10 to $21 \%$ of a standard deviation in WEMWBS score (based on WEMWBS score $\mathrm{SD}=8$ ). Adjustment for covariates had a similar impact on effect estimates across cohorts; few of the adjustments for individual covariates attenuated the associations greatly with the exception of adjustment for neuroticism (results not shown). In fully adjusted models, associations between physical capability and WEMWBS remained, albeit attenuated (Table 3).

There was little evidence of heterogeneity between studies of the walking and chair rise speed associations with WEMWBS (Table 3) and only moderate levels of heterogeneity between studies of grip strength associations, although confidence intervals were wide. The two studies of TUG speed-WEMWBS were heterogeneous, with a stronger association found in CaPS than in HCS (see Fig. 1).

Sensitivity analyses (results available on request) showed that if results for TUG speed in HCS were substituted in to meta-analyses of walking speed (in place of the HCS results on walking speed) this did not greatly affect the overall estimates of effect or estimates of between-study heterogeneity. However, inclusion of results on TUG speed in CaPS increased the overall estimate of effect and introduced heterogeneity between studies. There were no important differences in findings when models were rerun using the maximum available samples. In those cohorts where relevant information was available, mean WEMWBS scores of those unable to perform the tests of physical capability for health reasons were lower than the mean scores of those participants who did complete the tests, however the numbers of participants recorded as being unable to perform the tests were low. There was no consistent evidence to suggest that those participants who used a walking aid to complete the TUG test ( $n=16$ in CaPS and 11 in HCS) had different WEMWBS scores than those who performed the test unaided.

\section{Discussion}

This study presents consistent evidence of modest associations between objective measures of physical capability and positive mental wellbeing assessed between 5 and 10 years later across five older British cohorts. Most associations were maintained, albeit with attenuation, after adjustment for a range of potentially important confounding factors including health status and the personality trait of neuroticism.

\section{Comparison with other studies}

Mean levels of WEMWBS observed in the present study are similar to those reported in a recent national survey (Bromley et al. 2010). No study previously has related objective measures of physical capability to this relatively new wellbeing scale and few other studies have related them to any other measure of positive mental wellbeing. Previous analyses of HCS, LBC1921 and the Lothian Birth Cohort 1936, have reported associations of weaker grip strength with reduced levels of health-related quality of life (HRQoL) (Brett et al. 2012; Aihie Sayer et al. 2006), a construct related to mental wellbeing, and in two studies of older Swedish people slower walking speed (and also TUG speed in one of the studies) has also been linked to lower HRQoL (Ekstrom et al. 2011; Horder et al. 2012). However, these analyses were cross-sectional 


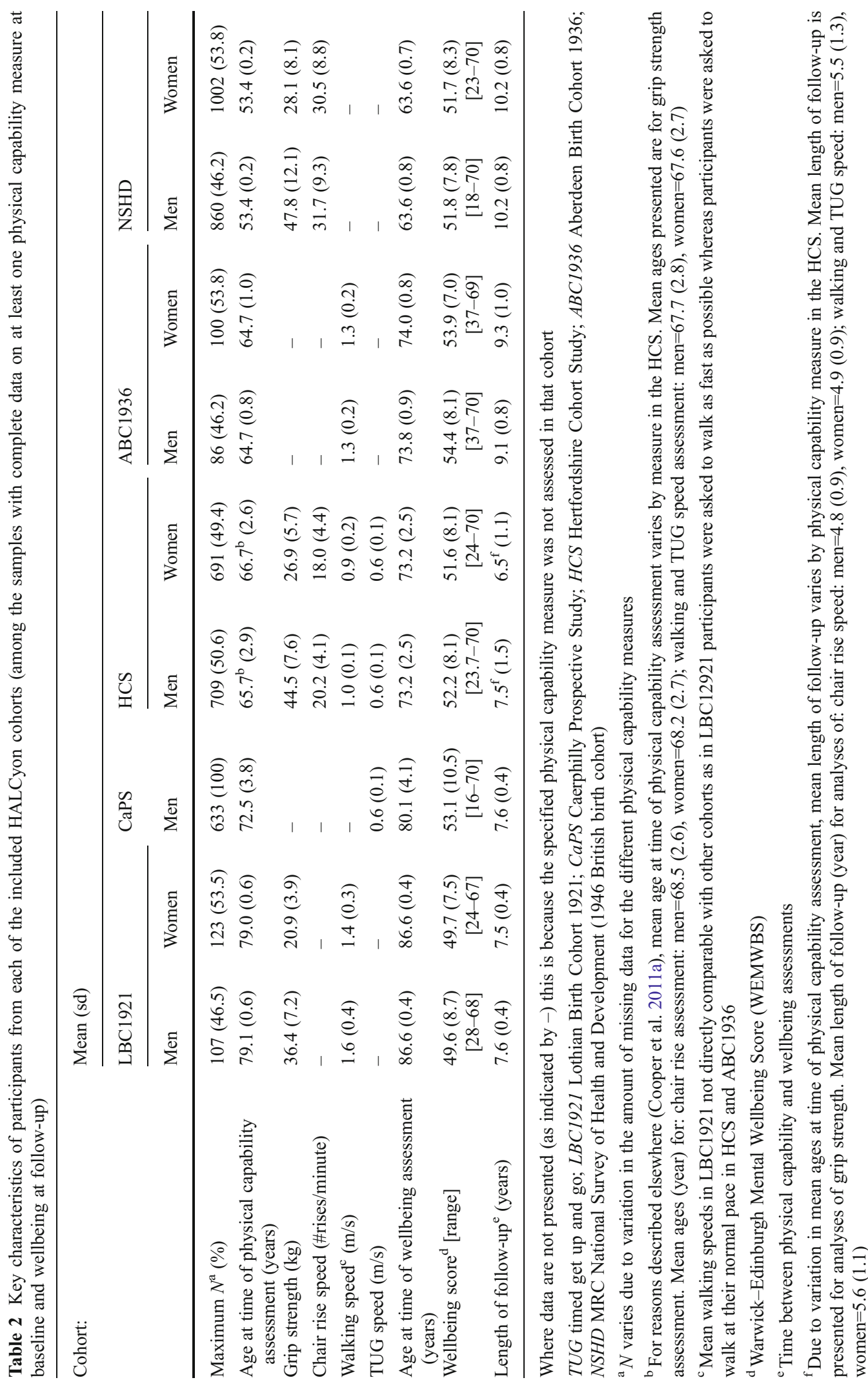


and each used different instruments to measure HRQoL that have different dimensions not all of which reflect mental wellbeing.

Our findings are also consistent with the limited evidence from previous longitudinal analyses using positive affect, a facet of mental wellbeing. In an older American population, lower self-reported physical functioning (as indicated by worsening performance in instrumental activities of daily living) was associated with a small decline in positive affect (Kurland et al. 2006), and in a German study of people aged 70 and over those people with more functional constraints, as indicated by a composite measure including mobility, were more likely to experience decline in positive affect over four years of follow-up (Kunzmann et al. 2000). Our work adds to this by showing that variation across the full range of physical capability is associated with subsequent positive mental wellbeing and that associations hold even when objective rather than self-reported measures of physical capability are used.

\section{Explanation of findings}

Our findings suggest that low or declining physical capability levels could be impacting on subsequent levels of wellbeing in older populations. This association could be acting directly or through associations of lower physical capability with increased risk of functional limitations and disability, outcomes which have been shown to negatively influence positive mental wellbeing (Kendig et al. 2000). That associations found were not fully explained by adjustment for a wide range of potentially important covariates suggests that our findings are unlikely to be due to confounding, although residual confounding is possible.

Qualitative work supports the suggestion that physical capability levels may influence subsequent wellbeing. In interviews conducted by Parsons et al. (2012) with subsamples of NSHD and HCS participants, 'general physical decline', 'slowing up' and 'being less able to do things' were some of the most frequently reported perceived disadvantages of ageing, with some interviewees feeling that this decline was associated with 'the withdrawal of respect and of being treated as a fully paid up member of society'. Lower levels of physical capability at any particular point in time, which may be indicative of prior experience of 'physical decline', could therefore justifiably be expected to affect subsequent positive mental wellbeing. 
Cross-sectional work showing that slower walking and TUG speeds are associated with a reduction in social participation (Ekstrom et al. 2011) provides evidence of a possible pathway by which lower levels of physical capability may influence subsequent wellbeing that should be investigated further.

Physical capability and wellbeing were temporally ordered in our analyses; however, as both physical capability and wellbeing are correlated over time, another possible explanation of our findings that cannot be ruled out is reverse causality. Wellbeing across life could influence lifestyle and other factors such as motivation to remain mobile and active and access to support networks and health care which affect the development or maintenance of physical capability and its subsequent decline. For example, a few longitudinal studies have shown that higher levels of different facets of positive mental wellbeing (i.e., positive affect, mastery and social participation) appear to protect against decline in physical capability in older populations (Buchman et al. 2009; Milaneschi et al. 2010; Ostir et al. 2000). In addition, low levels of wellbeing at the time of physical capability assessment could detrimentally influence performance. Further work to investigate the possible bidirectional nature of associations of physical capability with positive mental wellbeing, as has recently been undertaken in studies of physical capability and depression (Sanders et al. 2012), is thus required.

\section{Methodological considerations}

There are a number of strengths to this work including: an examination of associations across five British cohorts who represent a wide range of older ages (from 53 to 82 years at baseline) with birth years across the first half of the twentieth century; the use of the same validated measure of wellbeing (Tennant et al. 2007) across cohorts whereby we can be confident that differences between studies are not due to differences in instrument; the use of a range of harmonised objective, continuous measures of physical capability (Cooper et al. 2011a); and consistent adjustment for a range of important potential confounding factors in all cohorts.

By performing meta-analyses of results across cohorts, we were able to increase statistical power, make conclusions about consistency of findings across studies and demonstrate that similar associations between physical capability and subsequent mental wellbeing were found in cohorts of different ages and with different selection criteria. However, as only a maximum

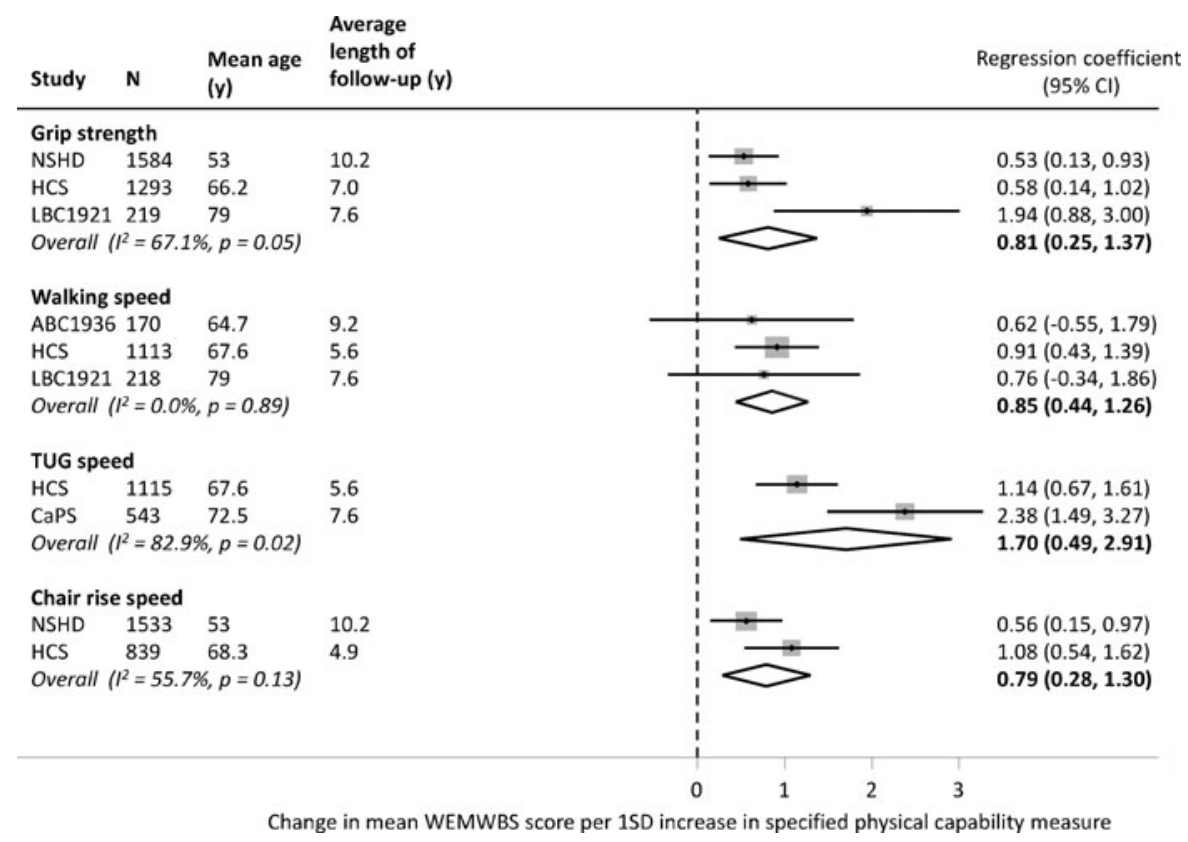

Fig. 1 Change in mean WEMWBS score per 1SD increase in specified capability measure 
of three studies were included in any one metaanalysis there was considerable uncertainty as to the true extent of heterogeneity (as indicated by the wide confidence intervals around our estimates of $I^{2}$ ) and we had insufficient power to explore possible sources of heterogeneity between studies such as age or length of follow-up. The fact that different studies had assessed different physical capability measures leads us to recommend caution in comparing the size of associations estimated between different measures of physical capability and wellbeing; the summary effect estimates from meta-analyses are not directly comparable as they each include different combinations of study populations.

The mean levels of physical capability reported in Table 2, in the samples of participants who also had data on WEMWBS at follow-up, are slightly higher than those reported previously in unrestricted samples at the same ages (Cooper et al. 2011a). These differences suggest that the participants who were not followed up had lower mean levels of physical capability at baseline than those who were, which may be explained by the fact that lower physical capability is associated with higher rates of death (Cooper et al. 2010), and death is expected to be an important reason for loss to follow-up in samples of this age. Given the expected direction of association, the loss to follow-up of people with lower levels of physical capability would be expected to have led to an underestimation in effect size. When analyses were run on maximum available samples the findings were the same, suggesting that further restrictions of the sample through exclusion of those with missing data on covariates did not introduce additional bias.

While a key strength of our work was the investigation of prospective associations between physical capability and subsequent wellbeing across five cohorts, a limitation is that we were unable to perform more elaborate analyses, such as dual change score models, to investigate the dynamic relationship between positive mental wellbeing and physical capability. This was because positive mental wellbeing had only been assessed in each cohort on one occasion, as had physical capability and covariates in the majority of cohorts. However, we have adjusted for key contributors to baseline wellbeing including health status, socioeconomic circumstances, personality, and living alone and, the covariate that caused the greatest attenuations in effect size was neuroticism which is expected to be stable over time.
As wellbeing was only ascertained at one time point in each study, we were unable to investigate withinindividual change in wellbeing. This is likely to be an interesting area for additional research, once further data have been collected, especially since evidence suggests that wellbeing remains relatively stable in later life, at least up to and including early old age (Charles and Carstensen 2010; Charles et al. 2001). According to socioemotional selectivity theory, this can be explained by the fact that as people get older awareness of the limited time left in life motivates them to regulate their social activities to maximize positive social interactions and emotional fulfilment and so maintain their wellbeing (Carstensen 1992; Carstensen et al. 1999; Charles and Carstensen 2010).

Future work could also build on our findings to investigate, in those studies where data are available, whether, for example, changes in physical capability (in addition to variation at one time point) influence subsequent wellbeing, whether these associations are independent of prior wellbeing and whether there are interactions with functional limitations and disability (i.e. is the association stronger if low physical capability is accompanied by reports of being unable to perform daily tasks?). In addition, as the WEMWBS is a measure of general mental wellbeing, the extent to which physical capability is related to specific dimensions of wellbeing such as self-esteem, life satisfaction or positive affect also warrants further investigation.

\section{Conclusions}

This study provides evidence that, in addition to their associations with mortality and subsequent health, objective measures of physical capability are also associated with subsequent positive mental wellbeing. Associations were consistent across five studies spanning early and later old age and across multiple measures of physical capability. While further in-depth work is required to investigate the directions of associations and underlying explanations of these findings, they highlight the importance of maintaining physical capability in later life and provide additional justification for using these measures as markers of healthy ageing.

Acknowledgements We are very grateful to all the cohort members who have participated in the studies included in 
HALCyon and all those involved in data collection. We also thank Truda Bell, Alan J Gow, Holly E. Syddall and Julie Withey for their help with data provision.

Open Access This article is distributed under the terms of the Creative Commons Attribution License which permits any use, distribution, and reproduction in any medium, provided the original author(s) and the source are credited.

\section{References}

Aihie Sayer A, Syddall HE, Martin HJ, Dennison EM, Roberts $\mathrm{HC}$, Cooper C (2006) Is grip strength associated with healthrelated quality of life? Findings from the Hertfordshire Cohort Study. Age Ageing 35:409-415

Beddington J, Cooper CL, Field J, Goswami U, Huppert FA, Jenkins R, Jones HS, Kirkwood TB, Sahakian BJ, Thomas SM (2008) The mental wealth of nations. Nature 455:10571060

Brett CE, Gow AJ, Corley J, Pattie A, Starr JM, Deary IJ (2012) Psychosocial factors and health as determinants of quality of life in community-dwelling older adults. Qual Life Res 21:505-516

Bromley C, Corbett J, Day J, Doig M, Gharib W, Given L, Gray L, Leyland A, MacGregor A, Marryat L, Maw T, McConnville S, McManus S, Mindell J, Pickering K, Roth M, Sharp C (2010) Scottish Health Survey 2010 - Volume 1: Main report. Bromley C, Given L, editors. National Statistics Publication for Scotland, 2010

Buchman AS, Boyle PA, Wilson RS, Fleischman DA, Leurgans S, Bennett DA (2009) Association between late-life social activity and motor decline in older adults. Arch Intern Med 169:1139-1146

Carstensen LL (1992) Social and emotional patterns in adulthood-support for socioemotional selectivity theory. Psychol Aging 7:331-338

Carstensen LL, Isaacowitz DM, Charles ST (1999) Taking time seriously - a theory of socioemotional selectivity. Am Psychol 54:165-181

Charles ST, Carstensen LL (2010) Social and emotional aging. Annu Rev Psychol 61:383-409

Charles ST, Reynolds CA, Gatz M (2001) Age-related differences and change in positive and negative affect over 23 years. J Pers Soc Psychol 80:136-151

Christensen K, Doblhammer G, Rau R, Vaupel JW (2009) Ageing populations: the challenges ahead. Lancet 374:1196-1208

Cooper R, Kuh D, Hardy R, Mortality Review Group (2010) Objectively measured physical capability levels and mortality: systematic review and meta-analysis. BMJ 341:c4467

Cooper R, Hardy R, Aihie Sayer A, Ben-Shlomo Y, Birnie K, Cooper C, Craig L, Deary IJ, Demakakos P, Gallacher J, McNeill G, Martin RM, Starr JM, Steptoe A, Kuh D (2011a) Age and gender differences in physical capability levels from mid-life onwards: the harmonisation and meta-analysis of data from eight UK cohort studies. PLoS One 6:e27899

Cooper R, Kuh D, Cooper C, Gale CR, Lawlor DA, Matthews F, Hardy R (2011b) Objective measures of physical capability and subsequent health: a systematic review. Age Ageing 40:14-23

Costa PT, McRae RR (1992) NEO PI-R Professional Manual. Psychological Assessment Resources, Odessa, FL

Deary IJ, Whiteman MC, Starr JM, Whalley LJ, Fox HC (2004) The impact of childhood intelligence on later life: following up the Scottish mental surveys of 1932 and 1947. J Pers Soc Psychol 86:130-147

Deary IJ, Gow AJ, Pattie A, Starr JM (2013) Cohort Profile: The Lothian Birth Cohorts of 1921 and 1936. Int J Epidemiol 41:1576-1584

DerSimonian R, Laird N (1986) Meta-analysis in clinical trials. Control Clin Trials 7:177-188

Ekstrom H, Dahlin-Ivanoff S, Elmstahl S (2011) Effects of walking speed and results of timed get-up-and-go tests on quality of life and social participation in elderly individuals with a history of osteoporosis-related fractures. J Aging Health 23:1379-1399

Eysenck H (1958) A short questionnaire for the measurement of two dimensions of personality. J Appl Psychol 42:14-17

Foresight Mental Capital and Wellbeing Project (2008) Final project report - executive summary. The Government Office for Science, London, UK

Forgeard MJC, Jayawickreme E, Kern ML, Seligman MEP (2011) Doing the right thing: measuring wellbeing for public policy. Int J Wellbeing 1:79-106

Gale CR, Aihie Sayer A, Cooper C, Dennison EM, Starr JM, Whalley LJ, Gallacher JE, Ben-Shlomo Y, Kuh D, Hardy R, Craig L, Deary IJ (2011) Factors associated with symptoms of anxiety and depression in five cohorts of communitybased older people: the HALCyon (Healthy Ageing across the Life Course) Programme. Psychol Med 41:2057-2073

Goldberg LR (2001) International Personality Item Pool. Available at: http://ipip.ori.org/ipip/

Higgins JP, Thompson SG (2002) Quantifying heterogeneity in a meta-analysis. Stat Med 21:1539-1558

Horder H, Skoog I, Frandin K (2012) Health-related quality of life in relation to walking habits and fitness: a populationbased study of 75-year-olds. Qual Life Res. doi:10.1007/ s11136-012-0267-7

Kendig H, Browning CJ, Young AE (2000) Impacts of illness and disability on the well-being of older people. Disabil Rehabil 22:15-22

Kuh D, Pierce M, Adams J, Deanfield J, Ekelund U, Friberg P, Ghosh AK, Harwood N, Hughes A, Macfarlane PW, Mishra G, Pellerin D, Wong A, Stephen AM, Richards M, Hardy R (2011) Cohort profile: updating the cohort profile for the MRC National Survey of Health and Development: a new clinic-based data collection for ageing research. Int $\mathrm{J}$ Epidemiol 40:e1-e9

Kuh D, Cooper R, Richards M, Gale C, von Zglinicki T, Guralnik J (2012) A life course approach to healthy ageing: the HALCyon programme. Public Health 126:193-195

Kunzmann U, Little TD, Smith J (2000) Is age-related stability of subjective well-being a paradox? Cross-sectional and longitudinal evidence from the Berlin Aging Study. Psychol Aging 15:511-526

Kurland BF, Gill TM, Patrick DL, Larson EB, Phelan EA (2006) Longitudinal change in positive affect in communitydwelling older persons. J Am Geriatr Soc 54:1846-1853

Li X, Wang W, Gao Q, Wu L, Luo Y, Tang Z, Guo X (2012) The trajectories and correlation between physical limitation and 
depression in elderly residents of Beijing, 1992-2009. PLoS One 7:e42999

Milaneschi Y, Bandinelli S, Corsi AM, Vazzana R, Patel KV, Ferrucci L, Guralnik JM (2010) Personal mastery and lower body mobility in community-dwelling older persons: the Invecchiare in Chianti study. J Am Geriatr Soc 58:98-103

Ostir GV, Markides KS, Black SA, Goodwin JS (2000) Emotional well-being predicts subsequent functional independence and survival. J Am Geriatr Soc 48:473-478

Parsons S, Gale CR, Kuh D, Elliott J (2012) Physical capability and the advantages and disadvantages of ageing: perceptions of older age by men and women in two British cohorts. Ageing Soc. doi:10.1017/S0144686X12001067

Phelan EA, Anderson LA, LaCroix AZ, Larson EB (2004) Older adults' views of "successful aging"- how do they compare with researchers' definitions? J Am Geriatr Soc 52:211-216

Podsiadlo D, Richardson S (1991) The timed up and go-a test of basic functional mobility for frail elderly persons. J Am Geriatr Soc 39:142-148

Sanders JB, Bremmer MA, Deeg DJ, Beekman AT (2012) Do depressive symptoms and gait speed impairment predict each other's incidence? A 16-year prospective study in the community. J Am Geriatr Soc 60:1673-1680

Self A, Thomas J, Randall C (2012) Measuring national well-being: life in the UK. Office for National Statistics, London, UK

Spielberger CD, Gorsuch RL, Lushene PR, Vagg PR, Jacobs AG (1983) Manual for the State-Trait Anxiety Inventory (Form Y). Consulting Psychologists, Palo Alto, CA

Stewart-Brown S, Janmohamed K (2008) Warwick-Edinburgh Mental Well-being Scale: User guide Version 1. Available at: http://www.healthscotland.com/uploads/documents/7551WEMWBS\%20User\%20Guide\%20Version $\% 201 \%$ 20June\%202008.pdf
Stiglitz JE, Sen A, Fitoussi J-P (2009) Report by the Commission on the Measurement of Economic Performance and Social Progress. Available at: http://www.stiglitz-senfitoussi.fr/ documents/rapport_anglais.pdf Accessed 16 January 2013

Studenski S, Perera S, Patel K, Rosano C, Faulkner K, Inzitari M, Brach J, Chandler J, Cawthon P, Connor EB, Nevitt M, Visser M, Kritchevsky S, Badinelli S, Harris T, Newman AB, Cauley J, Ferrucci L, Guralnik J (2011) Gait speed and survival in older adults. JAMA 305:50-58

Syddall HE, Aihie Sayer A, Dennison EM, Martin HJ, Barker DJ, Cooper C (2005) Cohort profile: the Hertfordshire cohort study. Int J Epidemiol 34:1234-1242

Tennant R, Hiller L, Fishwick R, Platt S, Joseph S, Weich S, Parkinson J, Secker J, Stewart-Brown S (2007) The Warwick-Edinburgh Mental Well-being Scale (WEMWBS): development and UK validation. Health Qual Life Outcomes 5:63

The Caerphilly and Speedwell Collaborative Group (1984) Caerphilly and Speedwell collaborative heart disease studies. J Epidemiol Community Health 38:259-262

Wadsworth M, Kuh D, Richards M, Hardy R (2006) Cohort Profile: the 1946 National Birth Cohort (MRC National Survey of Health and Development). Int $\mathrm{J}$ Epidemiol 35:49-54

Weich S, Brugha T, King M, McManus S, Bebbington P, Jenkins R, Cooper C, McBride O, Stewart-Brown S (2011) Mental well-being and mental illness: findings from the Adult Psychiatric Morbidity Survey for England 2007. Br J Psychiatry 199:23-28

World Health Organization, Department of Mental Health and Substance Abuse in collaboration with the Victorian Health Promotion Foundation (VicHealth) and the University of Melbourne (2004) Promoting mental health: concepts, emerging evidence, practice: summary report. World Health Organization, Geneva 